\begin{tabular}{|c|c|c|c|}
\hline \multirow{3}{*}{$\begin{array}{r}\text { Case Reports in } \\
\text { Gastroenterology }\end{array}$} & \multirow{2}{*}{\multicolumn{2}{|c|}{ Case Rep Gastroenterol 2016;10:241-247 }} & \multirow[b]{3}{*}{$\begin{array}{l}\text { Karger } \\
\text { Open'access }\end{array}$} \\
\hline & & & \\
\hline & $\begin{array}{l}\text { DOI: } 10.1159 / 000446576 \\
\text { Publisned onine: TViay } 27,2016\end{array}$ & $\begin{array}{l}\text { (c) } 2016 \text { The Author(s) } \\
\text { Published by S. Karger AG, Basel } \\
\text { www.karger.com/crg }\end{array}$ & \\
\hline & $\begin{array}{l}\text { This article is licensed under } \\
\text { International License (CC BY-N } \\
\text { Usage and distribution for comm }\end{array}$ & $\begin{array}{l}\text { mons Attribution-NonCommercia } \\
\text { ger.com/Services/OpenAccessLice } \\
\text { uires written permission. }\end{array}$ & \\
\hline
\end{tabular}

\title{
Synchronous Upper and Lower Gastrointestinal Mucosa-Associated Lymphoid Tissue Lymphomas
}

\author{
Michael McFarlane $^{\mathrm{a}} \quad$ John Lin Hieng Wong ${ }^{\mathrm{a}} \quad$ Shankara Paneesha $^{\mathrm{b}}$ \\ Zbigniew Rudzki ${ }^{c}$ Ramesh Arasaradnam ${ }^{a}$ Chuka Nwokolo ${ }^{a}$ \\ ${ }^{a}$ Department of Gastroenterology, UHCW, Coventry, United Kingdom; ${ }^{b}$ Department of \\ Haematology, Heart of England NHS Trust, Birmingham, United Kingdom; 'Department of \\ Histopathology, Heart of England NHS Trust, Birmingham, United Kingdom
}

\author{
Keywords \\ MALToma · Synchronous · Upper · Lower · Gastrointestinal
}

\begin{abstract}
Mucosa-associated lymphoid tissue lymphoma (MALToma) is a subtype of B-cell nonHodgkin's lymphoma, comprising $\sim 17 \%$ of all gastrointestinal (GI) tract lymphomas. It is associated with chronic inflammation and autoimmunity, for example Helicobacter pylori gastritis and Sjogren's syndrome, respectively. Approximately 50\% of GI MALTomas occur in the stomach, with small bowel and colonic lesions being less frequent. Synchronous upper and lower GI MALTomas occur rarely, with few cases reported. We present the case of a 73-yearold patient who presented with change in bowel habit and was found to have synchronous multifocal upper and lower GI MALTomas, which did not respond to $H$. pylori cure or to rituximab therapy, but did respond to a combination of surgery and chemotherapy with rituximab and bendamustine.

(C) 2016 The Author(s)

Published by S. Karger AG, Basel
\end{abstract}

\section{Introduction}

The gastrointestinal tract (GI) is a common site of presentation for extranodal lymphomas, which comprise between 5 and $10 \%$ of all primary GI neoplasms [1]. The commonest

\section{KARGER}


type of primary GI lymphoma is diffuse large B-cell lymphoma, which is a type of nonHodgkin's lymphoma and accounts for about 45\% of all cases of primary GI lymphoma [1]. Mucosa-associated lymphoid tissue lymphoma (MALT lymphoma or MALToma), also known as extranodal marginal zone B-cell lymphoma, is a subtype of B-cell non-Hodgkin's lymphoma and comprises approximately $17 \%$ of all GI tract lymphomas.

MALT is part of the normal host immune system of the GI tract. Peyer's patches, found in the small intestine, are examples of prominent, normal MALT. When triggered, the MALT provides a localised response to an antigenic challenge. Antigenic stimulus in the GI tract, e.g. Helicobacter pylori (HP) infection in the stomach, leads to the activation of the GI immune response and the proliferation of MALT. In the presence of sustained antigenic stimulus, lymphocytes within the MALT can undergo carcinogenesis and proliferate within the benign MALT, resulting in a MALToma [1].

MALTomas are not limited to the GI tract and can occur at any site in which MALT is able to proliferate. They can arise not only in response to the chronic inflammation seen in infections such as HP gastritis, but also in response to the chronic inflammation seen in autoimmune conditions such as Sjogren's syndrome, where they can occur in the salivary glands and in the thyroid in response to Hashimoto's thyroiditis [1].

The commonest GI site of MALToma is the stomach, with approximately $50 \%$ of lesions arising here, most commonly in response to chronic HP infection. Less common sites include the small bowel, which accounts for 20-30\%, and the colon, with colonic MALTomas being relatively rare and only accounting for approximately $10 \%$ of all GI MALTomas [1].

Although MALTomas themselves are not uncommon, the presence of synchronous upper and lower GI MALTomas appears to be a more rare occurrence, with only a few cases reported [2-4].

Here we present a case of synchronous upper and lower GI MALTomas and the potential management difficulties of MALTomas.

\section{Case Report}

A 73-year-old man with type 2 diabetes mellitus was referred from primary care with a 4-month history of alternating bowel habit associated with excessive mucus. There was no rectal bleeding and he did not have any abdominal pain, nor had he lost any weight. Physical examination revealed no evidence of anaemia or lymphadenopathy. His abdomen was soft and non-tender and there were no palpable masses or organomegaly. Digital rectal examination was unremarkable. His laboratory investigations revealed haemoglobin $143 \mathrm{~g} / \mathrm{l}$, a white blood cell count of $3.1 \times 10^{9} / \mathrm{l}$, a neutrophil count of $1.7 \times 10^{9} / \mathrm{l}$, platelets $203 \times 10^{9} / \mathrm{l}$, sodium $140 \mathrm{mmol} / \mathrm{l}$, potassium $5.1 \mathrm{mmol} / \mathrm{l}$, urea $7.8 \mathrm{mmol} / \mathrm{l}$, creatinine $94 \mu \mathrm{mol} / \mathrm{l}$, albumin $43 \mathrm{~g} / \mathrm{l}$, bilirubin $4 \mu \mathrm{mol} / \mathrm{l}$, alanine aminotransferase $15 \mathrm{IU} / \mathrm{l}$ and alkaline phosphatase $36 \mathrm{IU} / \mathrm{l}$. He underwent a colonoscopy, which revealed a large $5-\mathrm{cm}$, ulcerated, polypoid sigmoid lesion (fig. 1). Potential diagnoses at this point included colonic cancer, gastrointestinal stromal tumour (GIST) or MALToma. The biopsies from this lesion showed an intense lymphoid infiltrate, but no overt evidence of adenocarcinoma. Subsequent immunohistochemical (IHC) analysis showed a lymphoid infiltrate with numerous CD20+ B cells. BCL-2 was positive, whilst cyclin D1, CD10, CD43 and BCL6 were negative. There was no light chain restriction.

The patient underwent a staging CT scan, which confirmed the sigmoid lesion but also revealed a gastric cardia mass, but showed no evidence of other metastases. An oesophagogastroduodenoscopy revealed nodular gastritis throughout the corpus and a 30-mm 
spherical mass in the cardia with some proximal ulceration (fig. 2). He was HP positive by urease testing and on histology. He also underwent a linear endoscopic ultrasound which confirmed a $\sim 30$-mm smooth heterogenous hypoechoic lesion that involved mucosa, submucosa and the muscularis propria (fig. 3). Fine needle aspiration samples from the cardia mass revealed that there were no spindle cells present, which excluded a GIST. The biopsies from the gastric lesion, similarly to the sigmoid lesion, showed a dense lymphoid infiltrate and similar immunohistochemistry (fig. 4), with the exception that the gastric biopsies were CD43 positive on immunohistochemistry, whilst the colonic lesion was negative. This resulted in a diagnosis of synchronous upper and lower GI tract MALTomas, with differing immunohistochemistry patterns - multi-focal MALT lymphoma. Fluorescence in-situ hybridisation (FISH) studies of both sets of biopsies were conducted to assess for the presence of the MALT1 translocation - these were negative.

The patient underwent a sigmoid resection for the lesion which confirmed that the sigmoid lesion was a MALToma.

The gastric MALToma did not respond to either successful HP cure or a course of rituximab; however, after 3 cycles of bendamustine and rituximab chemotherapy, a repeat CT scan showed near complete resolution of the gastric lesion. This was confirmed with upper GI endoscopy (fig. 5).

\section{Discussion}

The diagnosis of MALToma usually relies on the careful application of histological and IHC analyses of the biopsy samples obtained during endoscopy. Histology will show the presence of lymphoepithelial lesions, defined by the infiltration and distortion of epithelial structures by aggregates of (usually three or more) neoplastic lymphoid cells [5]. Despite there being no specific IHC marker for MALToma, the IHC pattern is virtually identical to that of non-neoplastic marginal-zone B cells: CD20+, IgD-, IgM (>IgA>IgG)+, CD5-, CD10-, cyclin D1- [5].

Attempts have been made to determine the key endoscopic features which would suggest a lesion is a MALToma [6]. Gastric MALTomas have had a 6-point classification proposed: (1) exophytic: a single mass with irregular or polypoid aspect; (2) ulcerative: single to multiple ulcerations/erosions; (3) hypertrophic: enlarged folds and nodular pattern; (4) petechial haemorrhage: several petechiae at mucosal level; (5) normal/hyperemic mucosa: normal to reddish mucosa, and (6) mixed: more of the above-mentioned pattern present [7]. The role of endoscopic ultrasound was also covered and the authors concluded that 4 tumour patterns can be present: (1) superficial: where there is thickening of the second and third layers without involvement of either the first or fourth layer; (2) diffuse-infiltrative: diffuse trans-mural involvement of the gastric wall with irregular layer border and absence of uniform echogenicity; (3) mass-forming: localized hypoechoic mass at the third/fourth layer, with good demarcation from the surrounding tissue, and (4) mixed-type: a combination of the previous three patterns [7].

Colonic MALTomas are much rarer and make a consensus harder to arrive at, but the review suggested the usual endoscopic appearance is of a whitish polypoid lesion, usually not ulcerated and 1-2 cm in diameter, preserving a smooth aspect at endoscopy [6].

Gastric MALToma is regarded as an indolent disease, and the conventional treatment for low-grade gastric MALToma is HP cure. Approximately $20 \%$ of patients do not respond to HP cure and will require treatment with rituximab with or without chemotherapy [8]. Inter- 
McFarlane et al.: Synchronous Upper and Lower Gastrointestinal Mucosa-Associated Lymphoid Tissue Lymphomas

estingly, the absence of MALT1 translocation is usually an indicator of probable successful response to HP cure, although this was not the case in our patient. The treatment for colonic MALToma depends on the patients' age, co-morbidities, disease stage, etc., but usually involves a combination of surgery and/or rituximab +/- chemotherapy [conventionally CHOP (cyclophosphamide, doxorubicin, vincristine and prednisolone, although bendamustine with rituximab is also used] [8].

\section{Conclusion}

In this case, a 72-year-old man presented with a few months of altered bowel habit. He was found to have a sigmoid lesion, which later proved to be MALToma. A staging CT scan showed a synchronous gastric lesion, which was also found to be a MALToma after biopsy. Interestingly, the two lesions were shown to have a slightly different IHC profile, thus leading to a diagnosis of multifocal MALT lymphoma.

Although rare in the literature, the presence of cases such as this does raise the question of whether all patients with confirmed MALToma in the GI tract, especially gastric MALToma, should undergo staging CT and colonoscopy to exclude synchronous lesions. Complete staging has been suggested as mandatory by Fischbach [8] in his review on current MALToma diagnosis and management, and the classification should be based on either the AnnArbor system or the TMN system, although the latter has not been validated. Currently, patients with confirmed gastric MALToma are unlikely to have a CT scan due to the belief that it is an indolent disease. The detection of synchronous lesions will obviously affect their long-term prognosis and care, as synchronous lesions will likely require far more aggressive therapy than low-grade isolated gastric lesions.

\section{Statement of Ethics}

Case details and images used with patient's informed consent.

\section{Disclosure Statement}

The authors have no competing interest to declare.

\section{References}

1 O'Malley DP, Goldstein NS, Banks PM: The recognition and classification of lymphoproliferative disorders of the gut. Hum Pathol 2014;45:899-916.

-2 Jeong JH, Koo HS, Kang MG, Na WT, Lim DH, Huh KC: Synchronous primary low-grade mucosaassociated lymphoid tissue lymphoma of colon and stomach. Intest Res 2013;11:204-207.

-3 Venizelos J, Tamiolakis D, Nikolaidou S, Lambropoulou M, Alexiadis G, Papadopoulos N: Concurrent low grade B-cell non-Hodgkin's lymphoma of MALT type arising in the large intestine, small intestine and stomach. Chirurgia (Bucur) 2007;102:99-101.

4 Isomoto H, Yamasaki J, Kusakari C, Ohba K, Nishida Y, Kohno S: Simultaneous MALT lymphoma of stomach, duodenum, and colon. Gastrointest Endosc 2003;58:251-252.

5 Bacon CM, Du M-Q, Dogan A: Mucosa-associated lymphoid tissue (MALT) lymphoma: a practical guide for pathologists. J Clin Pathol 2007;60.4:361-372. 


\section{Case Reports in Gastroenterology}

\begin{tabular}{l|l}
\hline Case Rep Gastroenterol 2016;10:241-247 \\
\hline $10.1159 / 000446576$ & $\begin{array}{l}\text { C } 2016 \text { The Author(s). Published by S. Karger AG, Basel } \\
\text { www.karger.com/crg }\end{array}$ \\
\hline
\end{tabular}

McFarlane et al: Synchronous Upper and Lower Gastrointestinal Mucosa-Associated Lymphoid Tissue Lymphomas

6 Vetro C, et al: Endoscopic features of gastro-intestinal lymphomas: from diagnosis to follow-up. World J Gastroenterol 2014;20.36:12993-13005.

7 Zullo A, Hassan C, Cristofari F, Perri F, Morini S: Gastric low-grade mucosal-associated lymphoid tissuelymphoma: Helicobacter pylori and beyond. World J Gastrointest Oncol 2010;2:181-186.

-8 Fischbach W: Gastric MALT lymphoma - update on diagnosis and treatment. Best Pract Res Clin Gastroenterol 2014;28:1069-1077.

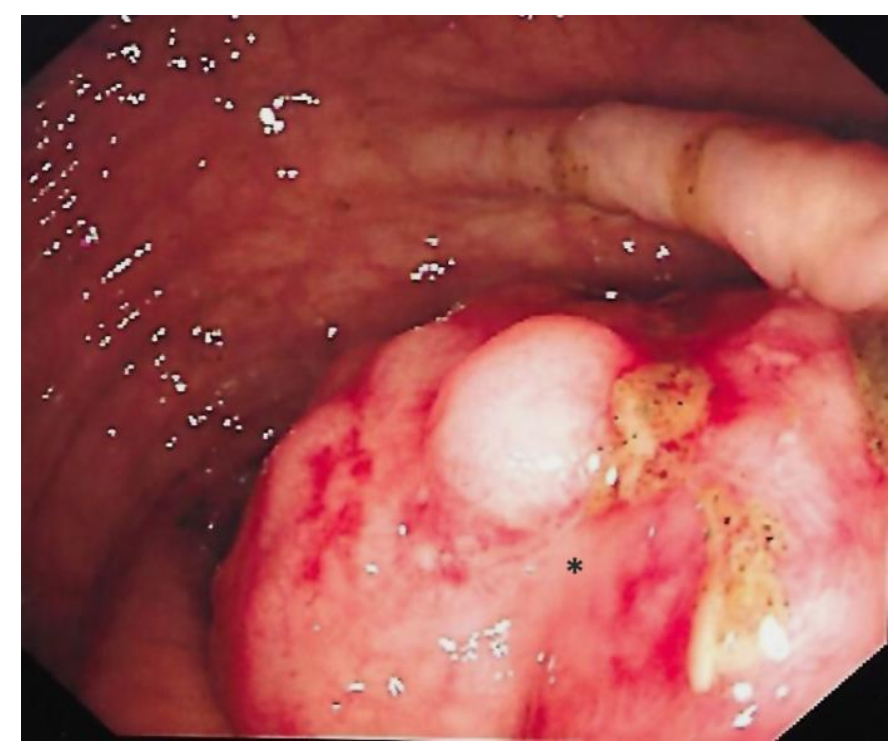

Fig. 1. Endoscopic image of a 50-mm polypoidal sigmoid lesion. The lesion is marked with an asterisk.

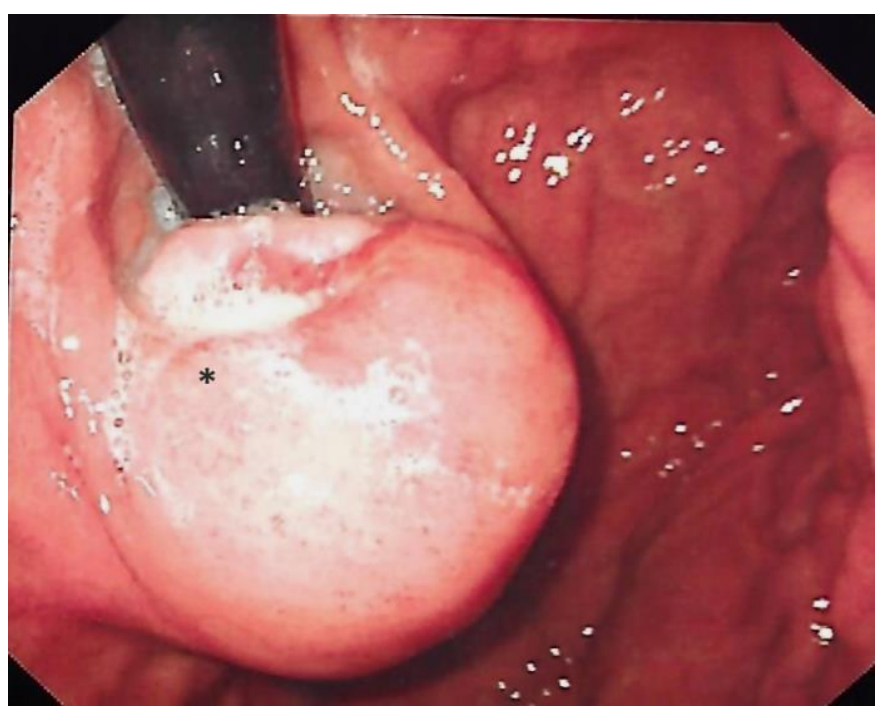

Fig. 2. Endoscopic image of a 30-mm gastric cardia lesion with unifocal ulceration. The lesion is marked with an asterisk. 


\section{Case Reports in Gastroenterology

\begin{tabular}{l|l}
\hline Case Rep Gastroenterol 2016;10:241-247 \\
\hline $10.1159 / 000446576$ & $\begin{array}{l}\text { ○ 2016 The Author(s). Published by S. Karger AG, Basel } \\
\text { www.karger.com/crg }\end{array}$ \\
\hline
\end{tabular} \\ McFarlane et al: Synchronous Upper and Lower Gastrointestinal Mucosa-Associated Lymphoid Tissue Lymphomas}

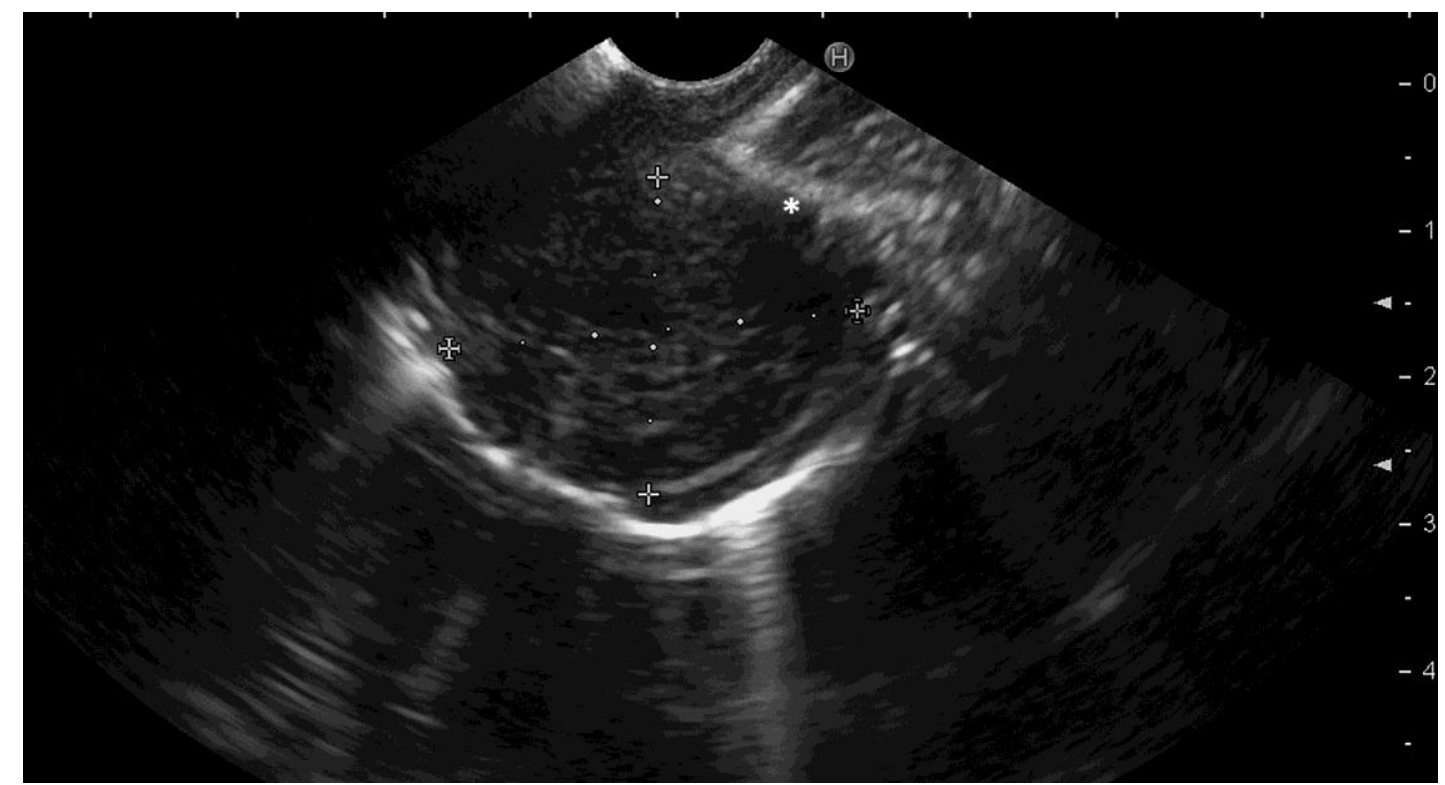

Fig. 3. Endoscopic ultrasound image of a $30-\mathrm{mm}$ gastric cardia lesion involving mucosa, submucosa and muscularis propria. The lesion is marked with an asterisk.

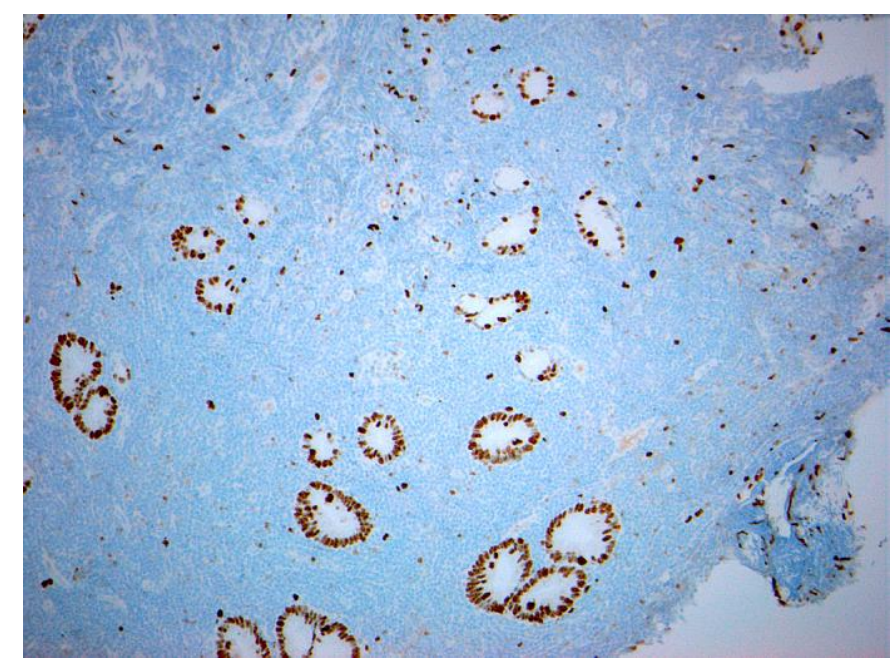

Fig. 4. Histological image of gastric cardia lesion biopsies with negative staining for cyclin D1. Objective magnification $\times 10$. Total magnification $\times 150$. 


\begin{tabular}{ll|l} 
Case Reports in & \multicolumn{2}{c}{ Case Rep Gastroenterol 2016;10:241-247 } \\
Gastroenterology & $\begin{array}{l}\text { 10.1159/000446576 } \\
\text { www.karger.com/crg }\end{array}$ \\
\cline { 2 - 3 } $\begin{array}{l}\text { McFarlane et al.: Synchronous } \\
\text { Lymphoid Tissue Lymphomas }\end{array}$
\end{tabular}

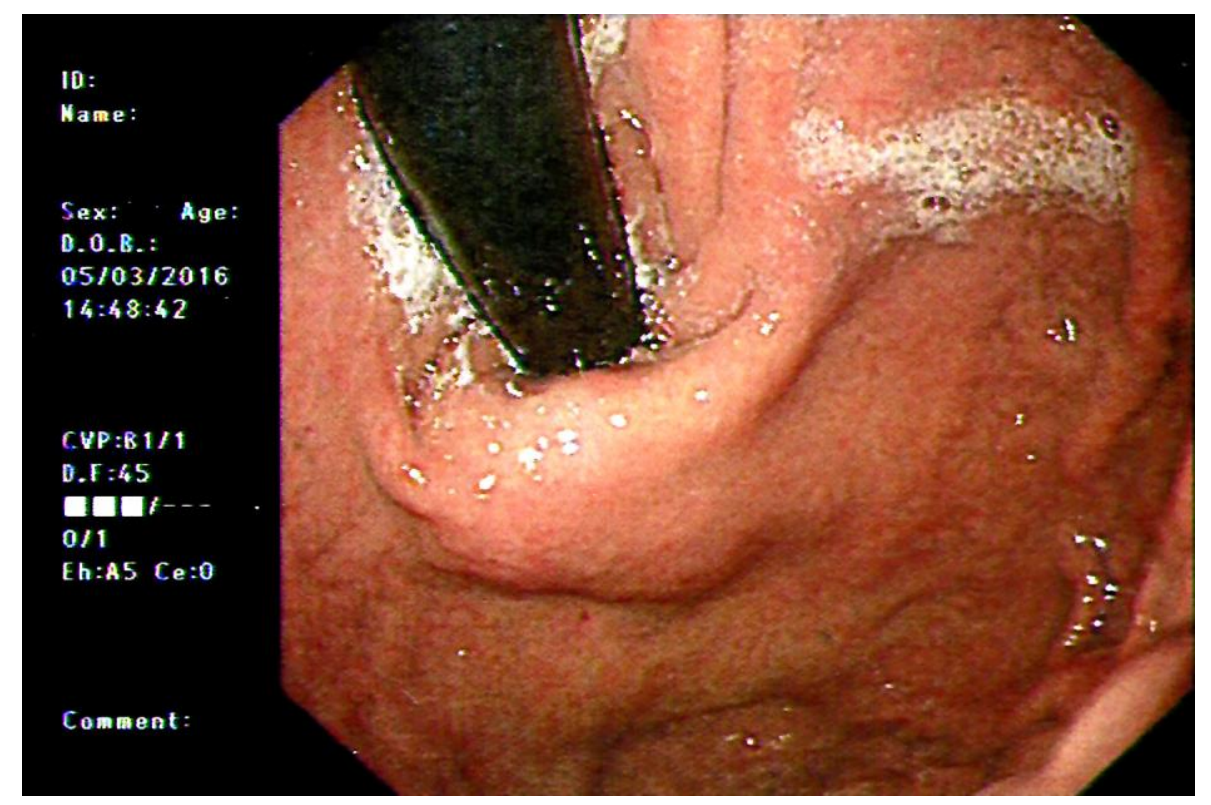

Fig. 5. Endoscopic image of gastric cardia after 3 cycles of bendamustine and rituximab chemotherapy. The gastric cardia lesion shows complete resolution. 